10-1-1997

\title{
Assembly and Disassembly of DNA Polymerase Holoenzyme
}

Daniel J. Sexton

Pennsylvania State University

Anthony J. Berdis

Cleveland State University, A.BERDIS@csuohio.edu

Stephen J. Benkovic

Pennsylvania State University

Follow this and additional works at: https://engagedscholarship.csuohio.edu/scichem_facpub

Part of the Chemistry Commons

How does access to this work benefit you? Let us know!

\section{Recommended Citation}

Sexton, Daniel J.; Berdis, Anthony J.; and Benkovic, Stephen J., "Assembly and Disassembly of DNA Polymerase Holoenzyme" (1997). Chemistry Faculty Publications. 171.

https://engagedscholarship.csuohio.edu/scichem_facpub/171

This Article is brought to you for free and open access by the Chemistry Department at EngagedScholarship@CSU. It has been accepted for inclusion in Chemistry Faculty Publications by an authorized administrator of EngagedScholarship@CSU. For more information, please contact library.es@csuohio.edu. 


\section{Assembly and disassembly of DNA polymerase holoenzyme Daniel J Sexton, Anthony J Berdis and Stephen J Benkovic}

The complex task of genomic replication requires a large collection of proteins properly assembled within the close confines of the replication fork. The mechanism and dynamics of holoenzyme assembly and disassembly have been investigated using steady state and pre-steady state methods as opposed to structural studies, primarily due to the intrinsic transient nature of these protein complexes during DNA replication. The key step in bacteriophage T4 holoenzyme assembly involves ATP hydrolysis, whereas disassembly is mediated by subunit dissociation of the clamp protein in an ATP-independent manner.

\footnotetext{
Abbreviations

FRET fluorescence resonance energy transfer

PCNA protiferating cell nuclear antigen

RF-C replication factor C
}

\section{Introduction}

In order to replicate genomic DNA quickly and accurately, a large collection of proteins is assembled at a strand-separated region of DNA known as a replication fork. These proteins minimally include a DNA polymerase which is responsible for catalyzing replication, a single-stranded DNA-binding protein which is responsible for holding open the replication fork, a DNA helicase, which unwinds the DNA region to be replicated, and a DNA primase which provides the priming sequences needed for lagging strand synthesis (Figure 1, Table 1). This large ensemble of replicative proteins requires intricate coordination, not only for proper function during the synthesis of both leading and lagging DNA strands during DNA replication but also during assembly and disassembly of these protein complexes at the appropriate time. The similaricies in composition and function among DNA replicases and their components suggest a unified mechanism for achieving proper coordination of the macroprocesses of assembly, DNA elongation, and disassembly of the replication fork.

The bacteriophage T4 DNA polymerase holoenzyme is derived from the phage DNA polymerase (the product of genc 43) and its accessory proteins (the products of genes 44, 45 and 62) [1,2]. 'The DNA polymerasc possesses a $3^{r} \rightarrow 5^{\prime}$ polymerization activity, as well as a $3^{\prime} \rightarrow 5^{\prime}$ exonuclease activity required for the maintenance of fidelity during replication, and has been extensively characterized kinetically $[3,4]$. As is the case for most replicases, however, the T4 polymerase alone incorporates nucleotides in a distributive manner, as opposed to the highly processive manner required for genomic replication in viva [5-7]. The processivity of the T4 DNA polymerase is increased by its interaction with replicative accessory proteins, which essentially prevent the polymerase from rapidly dissociating from the DNA. In this way these proteins afford an increase in the overall rate and processivity of both DNA synthesis and $3^{\prime} \rightarrow 5^{\prime}$ nucleotide excision catalyzed by the polymerase $[5,8,9]$.

\section{Fiqure 1}

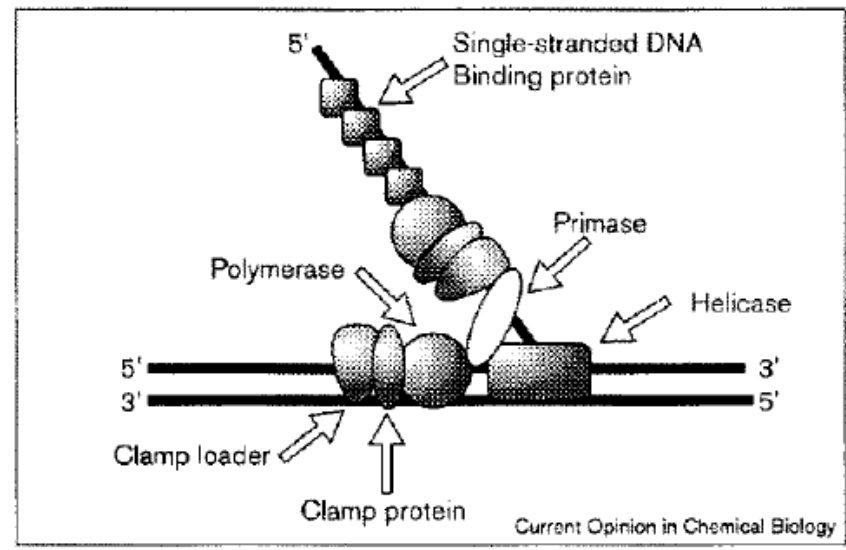

Model of bacteriophage T4 proteins at a DNA replication fork. The two holoenzymes are formed from the clamp-loader, the clamp protein, and the DNA polymerase; the helicase-primase constitutes the primosome which is responsible for movement of the replication fork and lagging strand Okazaki fragment priming. Although qualitatively similar in function, specific differences among the three well-defined replication systems are further addressed within the text.

The $44 / 62$ protein, generically referred to as the clamploader, places the sliding clamp, the 45 protein, onto DNA in an ATP-dependent manner [9]. The polymerase associates with the loaded clamp protein to form the stable holoenzyme on primer/templates. Because the $44 / 62$ protein and the 45 protein are functionally similar to the $\gamma$ complex [7] and the $\beta$ subunit [10], tespectively, in Escherichia coli, and to the replication factor C (RF-C) complex [11] and proliferating cell nuclear antigen (PC:NA) [12] in eukaryotic systems, we have used the relatively simple T4 replication system as a paradigm for understanding the roles and activities of the clamp-loader and clamp protein during assembly and disassembly of the processive holoenzyme complex. This review summarizes our current 
knowledge of the molecular mechanism and dynamics of holoenzyme assembly and disassembly, focusing primarily on these well-defined pathways in the bacteriophage T4 DNA replicative complex.

\section{Holoenzyme assembly}

Holoenzyme assembly proceeds by at least two ordered events: loading of the clamp protein by the clamp-loader, and rapid association of the polymerase with the loaded clamp protein to form the holoenzyme. Figure 2 presents a putative mechanism for $\mathrm{T} 4$ holoenzyme assembly, whereby clamp-loading onto the primer/template precedes interaction with the polymerase. The general features of T4 holoenzyme assembly appear to be species independent.

The crystal structures of the sliding clamp proteins from eukaryotes (PCNA), E coli ( $\beta$-clamp), and T4 (45 protein) have revealed a common ring-shaped structure with an interior diameter large enough to circumscribe double-stranded DNA (Table 1) $[13,14]$. The clamp proteins share several structural features, including a sidedness whereby only one face of the ring (the so-called rough face) apparently mediates protein-protein interactions $\left[15^{\bullet \bullet}, 16^{\bullet}\right]$ and the ability to slide on DNA [17], which is necessary for processive DNA synthesis. Consequently, primer/templates have been used that prevent translational dissociation from DNA by way of the presence of an upstream template biotin streptavidin complex and a downstream fork strand that simulates a replication fork [18]. Differences, however, do exist among the clamps with regards to quaternary structure (PCNA and the 45 protein are homotrimers whereas the $\beta$-clamp is a homodimer) and in their affinity for DNA ( $\beta$-clamp $>$ PCNA >45 protein; DJ Sexton, BF Kaboord, AJ Berdis, TE Carver, SJ Benkovic, unpublished data); [19••]).

Although it has not been directly demonstrated, the clamp proteins probably confer enhanced stability upon the holoenzyme through their concatenation with DNA. Under certain conditions, a fraction of either the 45 protein or PCNA can be assembled on linear DNA substrates in the absence of the clamp-loader [20,21]. Stoichiometric clamp-loading on DNA, however, always requires the ATP-hydrolysis-coupled activity of a dedicated clamp-loader protein complex. Clamp-loaders from eukaryotes, E. coli and T4 are multi-protein ATPase complexes (Table 1). The T4 clamp-loader is comprised of one 62 subunit and four 44 subunits, which contain the ATP-binding sites [22,23]. Each 44/62 complex noncooperatively binds four molecules of ATP [24**]. There appears to be some discrepancy as to the composition of the E. coli clamp-loader (DnaX or $\gamma$-complex), which varies from $\gamma_{4} \delta_{1} \delta^{\prime}{ }_{1} \chi_{1} \psi_{1}$ to $\gamma_{2} \delta_{1} \delta^{\prime}{ }_{1} \chi_{1} \psi_{1}[25,26]$. The $\gamma$-subunit of the E. coli clamp-loader binds two molecules of ATP per complex, which is consistent with the latter composition [27]. Recently, the eukaryotic clamp-loader from both humans and yeast (RF-C) has been reconstituted from its five purified subunits $[28,29]$.

While the exact functions of the individual clamp-loader subunits remain largely unknown, the overall role of the clamp-loader is to chaperone the clamp to the primer/template and catalyze ring opening. ATP binding invokes a conformational change in the $44 / 62$ complex that allows the 62 component of the complex to interact with the 45 protein [23]. This interaction occurs even in the absence of DNA to produce a stoichiometric $45 \cdot 44 / 62$ complex $\left[30^{\bullet \bullet}, 31^{\bullet \bullet}\right]$. A similar conformational change occurs in the $E$. coli $\gamma$-complex, which allows its $\delta$ protein component to interact with the $\beta$-clamp [32]. Indeed, cross-linking experiments have demonstrated the ability of the $44 / 62$ complex to chaperone the 45 protein to the primer/template [33]. This chaperone activity is dependent upon ATP binding but not hydrolysis, as ATP- $\gamma$-S also mediates the interaction of the $44 / 62$ protein with both DNA and the 45 protein $\left[31^{\bullet \bullet}, 33\right]$.

Table 1

Comparison of DNA replication systems.

\begin{tabular}{lll}
\hline Bacteriophage T4 & Escherichia coli & Eukaryotes \\
\hline 43 protein & DNA polymerase II & DNA polymerase $\alpha$ \\
43 protein & DNA polymerase III & DNA polymerase $\delta$ \\
$44 / 62$ complex & Subcomplexes of $\gamma, \delta, \delta^{\prime}, \chi_{+}$ & RF-C complex \\
45 protein & $\Psi, \tau$ subunits & \\
dnaN protein ( $\beta$ subunit) & PCNA
\end{tabular}

45 protein dnaN protein ( $\beta$ subunit)

pol $\alpha$-primase

61 protein

DnaG protein

41 protein

DnaB protein

32 protein

single-stranded binding protein
Dna2 protein

RF.A complex $(=\mathrm{RP} \cdot \mathrm{A}=\mathrm{SSB})$
Function

Leading-strand DNA synthesis Lagging-strand DNA synthesis DNA-dependent ATPase; stimulates DNA polymerase

Stimulates ATPase activity of $44 / 62$, $\gamma$-complex of RF-C; increases processivity of DNA polymerase: enhances primer binding of DNA polymerase

RNA-primer synthesis required for initiation of lagging-strand DNA synthesis Unwinds duplex DNA in $3^{\prime} \rightarrow 5^{\prime}$ direction; ATP-dependent Single-stranded DNA binding protein: binds to DNA co-operativity 
Although ATP binding to the clamp-loader is sufficient to enable initial association of the clamp with the primer template, ATP hydrolysis is required to load the 45 protein on the DNA strand, thereby stimulating T4 polymerase processivity $[34,35]$. Similar requirements for ATP hydrolysis hold for the E. coli and eukaryotic systems $[36,37]$. Presumably, ATP hydrolysis by the clamp-loader is coupled to a conformational change in the clamp protein, such as a ring-opening event. The mechanism whereby the energy of ATP hydrolysis is coupled to clamp-loading is not known, although a body of biochemical evidence suggests that the clamp-loader is a molecular motor with characteristics similar to the actin-myosin pair $\left[38^{\bullet \bullet}\right]$.

For the T4 system, the effect of varying the order of holoenzyme component addition on the rate of holoenzyme formation indicates that clamp-loading occurs before polymerase association (DJ Sexton, BF Kaboord, AJ Berdis, TE Carver, SJ Benkovic, unpublished data). Presteady state analysis of the ATPase activity of the 44/62 clamp-loader revealed that all four bound ATP molecules are hydrolyzed during the clamp-loading process, with rate constants in the range $1-15 \mathrm{~s}^{-1}[24 \cdot \bullet, 39 \cdot \bullet]$. Furthermore, ATP hydrolysis appears to occur sequentially during clamp-loading: two molecules of ATP are consumed at a rate of $\sim 14 \mathrm{~s}^{-1}$, then another two with a rate of $\sim 1 \mathrm{~s}^{-1}$ (Figure 2; DJ Sexton, BF Kaboord, AJ Berdis, TE Carver, SJ Benkovic, unpublished data). The lower pre-steady state rate of ATP hydrolysis is very similar to the rate of holoenzyme assembly $\left(\sim 1 \mathrm{~s}^{-1}\right)$, suggesting that ATP hydrolysis is somehow coupled to the rate-limiting assembly step $[39 \bullet \bullet, 40 \bullet \cdot$.

As expected, the ATP hydrolysis-coupled events are accompanicd by conformational changes in the 45 protein. Site-specific conjugation of the 45 protein to an environmentally sensitive fluorescent probe revealed an ATP-hydrolysis-dependent conformational change within the $45.44 / 62$ complex that occurred at a rate comparable to that of ATP hydrolysis $\left(\sim 14 \mathrm{~s}^{-1}\right.$; ) [31••]. In the presence of DNA, several conformational changes were observed in the fluorescently labeled 45 protein, one of which occurred at the limiting rate for holoenzyme assembly $\left(1 \mathrm{~s}^{-1}\right.$; DJ Sexton, BF Kaboord, AJ Berdis, TE Carver, SJ Benkovic, unpublished data). The rate-limiting step in clamp-loading in the E. coli system may also involve an ATP-hydrolysis-coupled conformational change $\left[41^{\bullet \bullet}\right]$.

Once clamp-loading is complete, the T4 polymerase rapidly associates under diffusion control to form the holoenzyme, in which the 45 protein interacts with the carboxyl terminus of the polymerase (Figure 2);

Figure 2

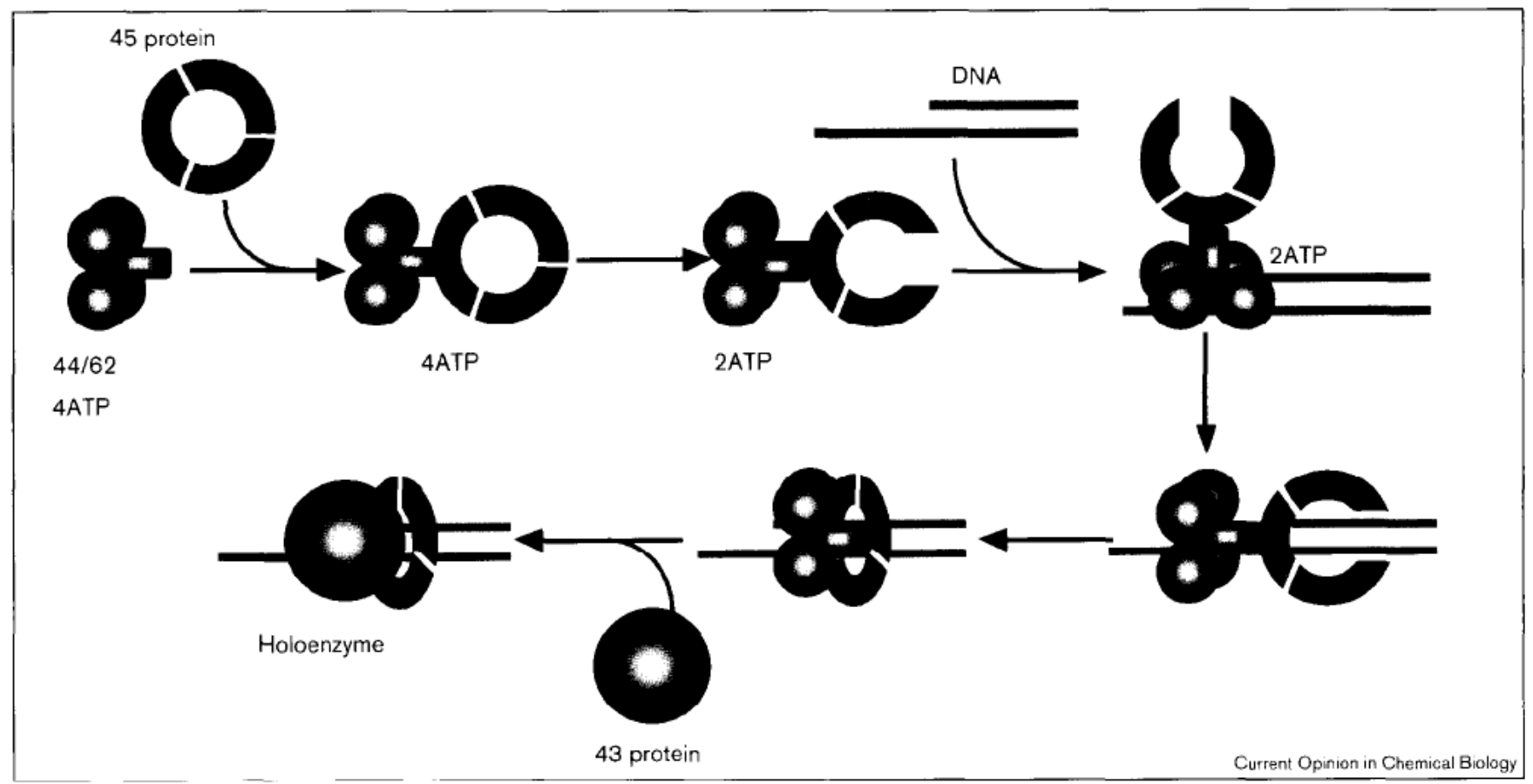

Proposed mechanism of bacteriophage T4 DNA polymerase holoenzyme assembly. The ATP-bound 44/62 complex is shown interacting first with the 45 protein, then with DNA. Two of the four bound ATPs are hydrolyzed prior to interaction with DNA. The resulting 45.44/62.DNA complex undergoes a conformational change, yielding a DNA.45.44/62 complex, followed by hydrolysis of remaining bound ATP. After both sets of ATP are hydrolyzed, the $45 \cdot 44 / 62$.DNA complex is poised for rapid association with the T4 polymerase (the 43 protein) and departure of the catalytic 44/62 complex, thus completing holoenzyme formation. 
(DJ Sexton, BF Kaboord, AJ Berdis, TE Carver, SJ Benkovic, unpublished data) [42*0]. The polymerase can conceivably interact with either a $45 . \mathrm{DNA}$ or a $45 \cdot 44 / 62$. DNA complex, depending on whether or not the clamp loader has already dissociated. The 45.44/62. DNA complex is probably preferred, as the $44 / 62$ complex functions as a molecular matchmaker for the introduction of the T4 polymerase into the holoenzyme [43,44]. Because the T4 clamp is loaded onto DNA catalytically, the clamp loader is not part of the final leading-strand holoenzyme complex $\left[39^{\circ}, 40^{\circ} \cdot\right.$. In the $E$. coli and eukaryotic systems, however, one clamp-loader remains associated between the leading- and lagging-strand holoenzyme dimer [26,45]. There are no reports for such an asymmetric complex in $\mathrm{T} 4$.

\section{Holoenzyme disassembly}

Although highly processive DNA synthesis is desirable for rapid completion of the leading strand, this mode of synthesis is not amenable for replication of the lagging strand. Specifically, the lagging-strand holoenzyme must be recycled after completion of one Okazaki fragment to move to the next fragment. This recycling problem can be alleviated by the proper disassembly of the lagging-strand holoenzyme, but this process must occur in a highly regulated fashion so as not to perturb continuous leading-strand DNA synthesis. Because ATP hydrolysis by the clamp loader is required for assembly of the holoenzyme, the clamp-loader should also participate in the ATP-dependent disassembly of the holoenzyme. However, the implication that this protein is not stably associated with the leading-strand holoenzyme means that the protein does not participate in disassembly, which must be mediated via an alternative mechanism.

In the search for a plausible mechanism of lagging-strand holoenzyme dissociation, kinetic experiments were performed that examined the stability of the holoenzyme complex once it encountered a completed Okazaki fragment (Figure 3a) [46]. Utilizing a defined primer/template designed to mimic an in vivo RNA primer, the kinetic consequence of the holoenzyme encountering this structure after processive DNA synthesis was examined by measuring the frequency at which the complex stalled or dissociated from the elongated DNA after encountering this structure. Measurements indicated that the holoenzyme preferred to dissociate upon encountering the hairpin rather than stall or perform strand-displacement synthesis, suggesting that the $5^{\prime}-\mathrm{OH}$ of the DNA segment is a signal that triggers the decomposition of the complex. To define further the molecular mechanism of this decomposition event, kinetic studies utilizing defined primer/templates containing either a DNA or RNA segment were recently performed (Figurc 3a; TE Carver, DJ Sexton and SJ Benkovic, unpublished data). These studies not only confirmed the frequency at which the holoenzyme dissociates, but they also uniquely demonstrated that the rate of the holoenzyme decomposition is stimulated 30 -fold by the presence of the RNA block $\left(k_{\text {dis }}=0.3 \mathrm{~s}^{-1}\right.$ versus $\left.k_{\text {off }}=0.01 \mathrm{~s}^{-1}\right)$, as required by the discontinuous nature of lagging-strand synthesis. In addition, the rate of decomposition was independent of the presence of the $44 / 62$ protein, consistent with its catalytic nature. Equally important, these measurements further demonstrated that the clamp and polymerase dissociate simultaneously.

Figure 3

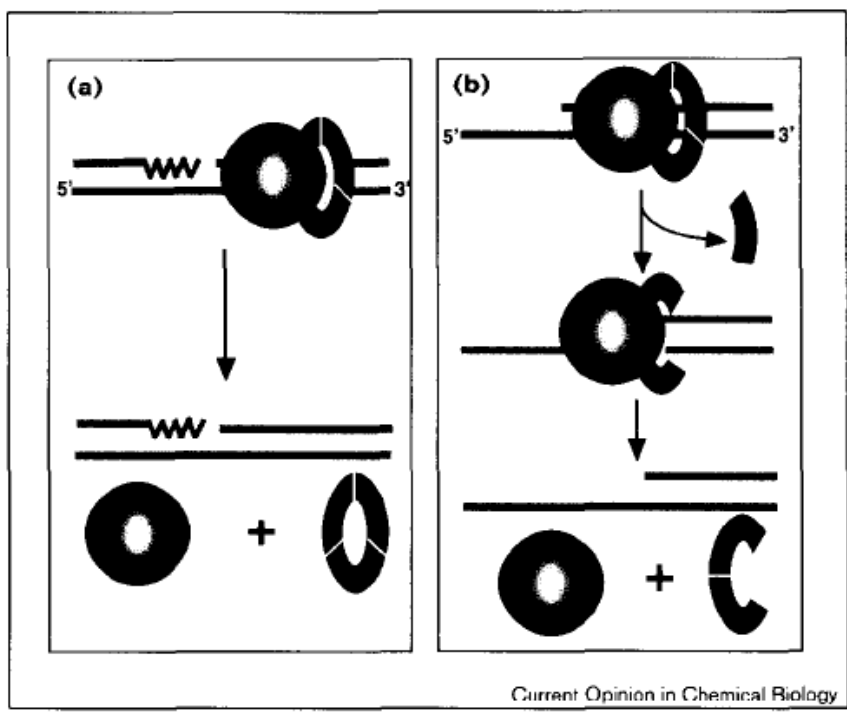

Proposed mechanisms for bacteriophage T4 DNA polymerase holoenzyme dissociation. (a) Upon encountering a previously completed Okazaki fragment (wavy line), the lagging-strand holoenzyme and the clamp protein are both triggered for rapid dissociation. (b) The more stable leading-strand holoenzyme appears to dissociate via a subunit-exchange mechanism, whereby the loss of a subunit from the $\mathbf{4 5}$ protein leads to holoenzyme dissociation. Holoenzyme components are represented by the same symbols as in Figure 2.

Incorporation of the 45 protein into the leading-strand holoenzyme complex increases the stability of the 45 protein on DNA at least 100 -fold ( $K_{\text {off }}$ decreases from $1 \mathrm{~s}^{-1}$ to $<0.01 \mathrm{~s}^{-1}$ ). One likely disassembly mechanism involves the loss of a subunit from the 45 protein within the holoenzyme complex (Figure 3b). Subunit exchange within the 45 protein has been measured using a variant of the 45 protein that facilitates observation of inter-subunit FRET (PS Soumillion, DJ Sexton, SJ Benkovic, unpublished data). Upon mixing this protein with a nonfluorescent form of the 45 protein that contains 4-fluorotryptophan, subunit exchange was observed to occur with a first order rate constant of about $0.01 \mathrm{~s}^{-1}$, which is very similar to the rate of holoenzyme dissociation $[31 \cdot \bullet, 43]$. The latter rate, which would apply to leading-strand synthesis, is sufficiently slow, given a rate of polymerization of approximately 500 nucleotides $\mathrm{s}^{-1}$, to accomplish processive replication of the $\mathrm{T} 4$ genome during a single pass of the holoenzyme. 
In contrast to the $\mathrm{T} 4$ system, the $E$. coli holoenzyme is able to quickly dissociate ( $k_{\mathrm{off}}<1 \mathrm{~s}^{-1}$ ) upon completion of DNA synthesis, during which only the polymerase dissociates, leaving the $\beta$ subunit behind [47]. The greater stability of the $\beta$ clamp on DNA has apparently necessitated a catalytic clamp-unloading activity that is accommodated by the E. coli $\gamma$ complex [48]. Even more intriguing is the observation that dissociation of the $\beta$-clamp requires ATP binding to the $\gamma$ complex but not ATP hydrolysis. It is likewise suggested that the dissociation rate of the eukaryoric holoenzyme is dictated by the release of the polymerase and not by PCNA [49]. The difference in decomposition of the holoenzymes suggests an inherent difference in recycling of the clamp, a difference that may impact on the coordination of leading- and lagging-strand DNA synthesis. It is unclear how ATP binding and hydrolysis by the clamp loaders are regulated with regards to assembly versus disassembly of the holoenzyme.

\section{Conclusions}

The mechanisms of bacteriophage T4 DNA polymerase holocnzyme assembly and disassembly have been well elucidated using a combination of kinetic and biophysical methodologies. The multitude of individual protein-protein and protein-DNA interactions, as well as internal protein conformational changes, confirms that DNA replication is indeed mediated by an elegant protein machine. Now that the replication components from many eukaryotes and various pathogens have been identified, further information on these replication systems requires detailed mechanistic analysis. The techniques used to study T4 assembly and disassembly mechanisms will prove useful when applied to other replication systems. Future challenges include dissection of the assembly/disassembly mechanisms of higher-ordered structures, such as the coordination of leading- and lagging-strand DNA synthesis, and the interactions that couple the holoenzyme to the helicase/primase $\left[50,51^{\bullet}, 52-54\right]$.

\section{References and recommended reading}

Papers of particular interest, published within the annual period of reviow, have been highlighted as:

- of special interest

- of outstanding interest

1. Young MC, Reddy MK, von Hippel PH: Structure and function of the bacteriophage T4 DNA polymerase holoenzyme. Biochemistry 1992, 31:8675-8690.

2. Nossal NG: The bacteriophage T4 DNA replication fork. In Molecular Biology of Bacteriophage. Edited by Karam JD. Washington DC: ASM Press; 1994.

3. Capson TL, Peliska JA, Kaboord BF, Frey MW, Lively C, Dahlberg M, Benkovic SJ: Kinetic characterization of the polymerase and exonuclease activities of the gene $\mathbf{4 3}$ protein of bacteriophage T4. Biochemistry 1992, 31:10984-10994.

4. Frey MW, Nossal NG, Capson TL, Benkovic SJ: Construction and characterization of a bacteriophage T4 DNA polymerase deficient in $3^{\prime} \rightarrow 5^{\prime}$ exonuclease activity. Proc Natl Acad Sci USA 1993, 90:2579-2583.

5. Mace DC, Alberts BM: T4 DNA polymerase rates and processivity on single-stranded DNA templates. J Mol Biol $1984,177: 295-311$.
6. Richardson CC: Bacteriophage T7: minimal requirements for the replication of a duplex DNA molecule. Cell 1983, 33:315. 317.

7. Maki S, Kornberg A: DNA polymerase III holoenzyme of Escherichia coli III: Distinctive processive polymerases reconstituted from purified subunits. J Biol Chem 1988, 263:6561-6569.

8. Venkatasan M, Nossal NG: Bacteriophage T4 gene 44/62 and gene $\mathbf{4 5}$ polymerase accessory proteins stimulate hydrolysis of duplex DNA by T4 DNA polymerase. J Biol Chem 1982. 257:12435-12443

9. Mace DC, Alberts BM: The complex of T4 bacteriophage gene 44 and 62 replication proteins forms an ATPase that is stimulated by DNA and by T4 gene 45 protein. J Mol Biol 1984, 177:279-293

10. Stukenburg PT, Studwell-Vaughn PS, O'Donneli M: Mechanism of the sliding $\beta$-clamp of DNA polymerase III holoenzyme. J Biol Chem 1991, 266:11328-11334.

11. Lee S-K. Kwong AD, Pan Z-Q. Hurwitz J: Studies on the activator 1 protein complex, an accessory factor for proliferating cell nuclear antigen-dependent DNA polymerase $\delta$. J Biol Chem 1991, 266:594-602.

12. Tsurimoto T, Stillman B: Multiple replication factors augment DNA synthesis by the two eukaryotic DNA polymerases, alpha and delta. EMBO J 1989, 8:3883-3889.

13. Kong XP, Onrust R, O'Donnell M, Kuriyan J: Three-dimensional structure of the beta subunit of $E$. coli DNA polymerase III holoenzyme: a sliding DNA clamp. Cell 1992, 69:425-437.

14. Krishna TS, Kong XP, Gary S, Burgers PM, Kuriyan J: Crystal structure of the eukaryotic DNA polymerase processivity factor PCNA. Cell 1994, 79:1233-1243.

15. Naktinis V, Turner J, O'Donnell M: A molecular switch in a .. replication machine defined by an internal competition for protein rings. Cell 1996, 84:137-145.

Demonstrates that the $\beta$-clamp interacts tightly with the $\gamma$ complex in the absence of DNA. However, once loaded onto DNA, association between the $\gamma$ complex and the $\beta$-clamp is diminished, thereby facilitating the interaction of the clamp protein with the polymerase on DNA to form the stable holoenzyme.

16. Mossi R, Jonsson ZO, Allen BL, Hardin SH, Hubscher U:

- Replication factor $C$ interacts with the C-terminal side of proliferating cell nuclear antigen. J Biol Chem 1997, 272:17691776.

Using a kinase protection assay, it is demonstrated that RF-C is able to protect the carboxy-terminal region but not the $\mathrm{N}$-terminal region of PCNA from phosphorylation. These data suggest that RF-C interacts with a specific face of PCNA, very similar to results obtained with the $\beta$-clamp in complex with its respective clamp loader.

17. Tinker RL, Kassavetis GA, Geiduschek EP: Detecting the ability of viral, bacterial and eucaryotic replication proteins to track along DNA. EMBO J 1994, 13:5330-5337.

18. Kaboord BF, Benkovic SJ: Rapid assembly of the bacteriophage T4 core replication complex on a linear primer/template construct. Proc Nat/ Acad Sci USA 1993, 90:10881-10885.

19. Yao N, Turner J, Kelman Z, Stukenberg PT, Pan Z-Q, Hurwitz J, .. O'Donnell M: Cycling of DNA sliding clamps of human, E. coli and T4 replicases. Genes Cells 1996, 1:101-113.

Examines the stability of the three various clamp proteins both free in solution and on DNA. Both PCNA and the $\beta$-clamp are highly stable on DNA with a half-life for the rate of dissociation greater than 20 minutes, thus necessitating the need for an unloading factor for proper disassembly. The clamp loaders of PCNA and the $\beta$-clamp serve as the unloading factors required for proper clamp recycling, in which both loading and unloading, of the clamp are ATP-dependent processes.

20. Reddy MK, Weitzel SE, von Hippel PH: Assembly of a functional replication complex without ATP hydrolysis: a direct interaction of bacteriophage T4 gp45 with T4 DNA polymerase. Proc Natl Acad Sci USA 1993, 90:3211-3215.

21. Burgers PMJ, Yoder BL: ATP-independent loading of the proliferating cell nuclear antigen requires DNA ends. J Biol Chem 1993, 268:19923-19926.

22. Rush J, Lin TC, Quinones M, Spicer EK, Douglas I, Williams KR, Konigsberg WH: The 44p subunit of the T4 DNA polymerase 
accessory protein catalyzes ATP hydrolysis. J Biol Chem 1989, 264:10943-10953.

23. Jarvis TC, Paul LS, von Hippel PH: Structural and enzymatic studies of the T4 DNA replication system: 1. Physical characterization of the polymerase accessory protein complex. $J$ Biol Chem 1989, 264:1 2709-12716.

24. Young MC, Weitzel SE, von Hippel PH: The kinetic mechanism -. of formation of the bacteriophage T4 DNA polymerase sliding clamp. $J$ Mol Biol 1996, 264:440-452.

These results suggest that the formation of a single T4 sliding clamp on DNA requires the hydrolysis of four ATP molecules by one 44/62 complex in a process lasting $0.5-1 \mathrm{~s}$

25. Dallmann HG, McHenry CS: DnaX complex of Escherichia coli DNA polymerase III holoenzyme: physical characterization of the DnaX subunits and complexes. J Biol Chem 1995. 270:29563-29569.

26. Onrust R, Finkelstein J, Naktinis V, Turner J, Fang L, O'Donnell M: Assembly of a chromosomal replication machine: two DNA polymerases, a clamp loader, and sliding clamp in one holoenzyme particle. I. Organization of the clamp loader. $J$ Biol Chem 1995, 270:13348.13357.

27. Burgers PM, Kornberg A: ATP activation of DNA polymerase III holoenzyme from Escherichia coli. II. Initiation complex: stoichiometry and reactivity. $J$ Biol Chem 1982, 257:1147411478.

28. Uhlman F, Cai J, Flores-Rozas H, Dean FB, Finkelstein J, O'Donnell M, Hurwitz J: In vitro reconstitution of human replication factor $\mathrm{C}$ from its five subunits. Proc Natl Acad Sci USA 1996, 93:6521-6526.

29. Gary SL, Burgers PMJ: Identification of the fifth subunit of Saccharomyces cerevisiae replication factor C. Nucleic Acids Res 1995, 23:4986-4991.

30. Latham GJ, Pietroni P, Dong F, Young MC, von Hippel PH:

-. Fluorescence monitoring of T4 polymerase holoenzyme accessory protein interactions during loading of the sliding clamp onto template-primer junction. $J$ Mol Biol 1996, 264:426439.

A site-specific (Ser $19 \rightarrow$ Cys) mutant of the $\mathbf{4 5}$ protein is derivatized with a fluorescent probe and used to detect a 1:1 complex between the 45 protein and the ATP activated 44/62 complex.

31. Sexton DJ, Carver TE, Berdis AJ, Benkovic SJ: Protein-protein -. and protein DNA interactions at the bacteriophage T4 DNA replication fork: characterization of a fluorescently labeled DNA polymerase sliding clamp. J Biol Chem 1996, 271:2804528051.

A site-specific (Thr $7 \rightarrow$ Cys) mutant of the 45 protein is modified with a fluorescent label and used to demonstrate that ATP-S could mediate complex formation between the 45 protein and the $44 / 62$ complex and support their binding to DNA. The onset of ATP hydrolysis triggers a conformationa change in the $\mathbf{4 5}$ protein that is associated with clamp-loading onto DNA.

32. Naktinis V, Onrust R, Fang L, O'Donnell M: Assembly of a chromosomal replication machine: two DNA polymerases, a clamp loader, and sliding clamps in one holoenzyme particle. II. Intermediate complex between the clamp loader and its clamp. J Biol Chem 1995, 270:13358-13365.

33. Capson TL, Benkovic SJ, Nossal NG: Protein-DNA cross-linking demonstrates stepwise ATP-dependent assembly of the T4 DNA polymerase and its accessory proteins on the primertemplate. Cell 1991, 65:249-258.

34. Gogol EP, Young MC, Kubasek WL, Janvis TC, von Hippel PH: Cryoelectron microscopic visualization of functional subassemblies of the bacteriophage T4 DNA replication complex. $J$ Mol Biol 1992, 224:395-412.

35. Jarvis TC, Paul LS, Hockensmith JW, von Hippel PH: Structural and enzymatic studies of the T4 DNA replication system: 2. ATPase properties of the polymerase accessory protein complex. J Biol Chem 1989, 264:12717-12729.

36. Onrust R, Stukenberg PT, O'Donnell M: Analysis of the ATPase subassembly which initiates processive DNA synthesis by DNA polymerase III holoenzyme. J Bio/ Chem 1991, 266:21681. 21686.

37. Burgers PMJ: Saccharomyces cerevisiae replication factor C: II. Formation and activity of complexes with the proliferating cell nuclear antigen and with DNA polymerases $\delta$ and $\varepsilon$. J Biol Chem 1991, 266:22698-22706.

38. Berdis AJ, Benkovic SJ: Mechanism of bacteriophage T4 DNA -. holoenzyme assembly: The $44 / 62$ protein acts as a molecular motor. Biochemistry 1996, 36:2733-2743.

The mechanism of ATP utilization by the $44 / 62$ protein during loading of the 45 protein onto duplex DNA is quantitatively examined by various kinetic and biophysical techniques. The mechanism of clamp-loading, especially with regards to ATP hydrolysis, is shown to be very similar to other molecular motors such as actin, kinesin, and dynein that also mediate protein movement.

39. Berdis AJ, Benkovic SJ: Role of ATP hydrolysis in the assembly -. of the bacteriophage T4 DNA replication holoenzyme complex. Biochemistry 1996, 35:9253-9265.

ATPase measurements of the $44 / 62$ protein during clamp-loading and holoenzyme formation are addressed by steady state and pre-steady state measurements. Four ATPs molecules are rapidly consumed by each 44/62 protein during clamp-loading, and the binding of polymerase to form the stable holoenzyme is independent of ATP hydrolysis.

40. Kaboord BF, Benkovic SJ: Dual role of the $44 / 62$ protein as a .. matchmaker protein and DNA polymerase chaperone during assembly of the bacteriophage T4 holoenzyme complex. Biochemistry 1996, 35:1084-1092.

Rapid quench kinetic methods are used to show that the active holoenzyme comprises a $1: 1$ complex of the 45 protein and polymerase. The $44 / 62 \mathrm{com}$ plex acts catalytically in the holoenzyme assembly, loading multiple copies of the $\mathbf{4 5}$ protein onto DNA. It also chaperones the polymerase to the loaded clamp protein, thus ensuring productive holoenzyme formation.

41. Bloom LB, Turner J, Kelman Z, Beechem JM, O'Donnell M,

-. Goodman MF: Dynamics of loading the beta sliding clamp of DNA polymerase III onto DNA. J Biol Chem 1996, 271:30699 30708 .

The ATP-dependent binding of the $\beta$-clamp by the $\gamma$ complex clamp loader was monitored by pre-steady state fluorescence measurements, which demonstrated that clamp assembly is rapid on the time scale required for lagging strand synthesis. The loading of the $\beta$-clamp is independent of the concentration of the proteins, suggesting that a step, possibly the opening of the clamp, is rate limiting for loading

42. Berdis AJ, Soumillion PS, Benkovic SJ: The carboxyl terminus

-. of the bacteriophage T4 DNA polymerase is required for holoenzyme complex assembly. Proc Natl Acad Sci USA 1996, 93:1 2822-12827.

The identity of the molecular contacts between the 45 protein and polymerase is determined by kinetic measurements using a deletion mutant of the T4 DNA polymerase. A minimal sequence of six hydrophobic amino acids is required for proper association between the clamp and polymerase.

43. Kaboord BF, Benkovic SJ: Accessory proteins function as matchmakers in the assembly of the T4 DNA polymerase holoenzyme. Curr Biol 1995, 5:149-157.

44. Sanders GM, Kassavetis GA, Geiduschek EP: Rules governing the efficiency and polarity of loading a tracking clamp protein onto DNA: determinants of enhancement in bacteriophage T4 late transcription. EMBO J 1995, 14:3966-3976.

45. Maga G, Hubscher U: DNA replication machinery: functional characterization of a complex containing DNA polymerase, DNA polymerase, and replication factor $C$ suggests an asymmetric DNA polymerase dimer. Biochemistry 1996 35:5764-5777.

46. Hacker $\mathrm{KJ}$, Alberts BM: The rapid dissociation of the T4 DNA polymerase holoenzyme when stopped by a DNA hairpin helix: a model for polymerase release following the termination of each okazaki fragment. $J$ Biol Chem 1994, 39:24221-24228.

47. O'Donnell M, Kornberg A: Dynamics of DNA polymerase III holoenzyme of Escherichia coli in replication of a mutiprimed template. J Biol Chem 1985, 260:12875-12883.

48. Stukenberg PT, Tumer J, O'Donnell M: An explanation for lagging strand replication: polymerase hopping among DNA sliding clamps. Cell 1994, 78:877-887. 
49. Podust VN, Podust LM, Mulle F, Hubscher U: DNA polymerase $\delta$ holoenzyme:action on single-stranded DNA and on doublestranded DNA in the presence of replicative DNA helicases. Biochemistry 1995, 34:3003-3010.

50. Stillman B: Smart machines at the DNA replication fork. Cell 1994, 78:725-728.

51. Bambara RA, Murante RS, Henricksen LA: Enzymes and

- reactions at the eukaryotic DNA replication fork. J Biol Chem 1997, 272:4647-4650.

An overview of recent findings concerning the requirements for growth of the eukaryotic replication fork.
52. Kim S, Dallmann HG, McHenry CS, Marians KJ: Coupling of a replicative polymerase and helicase: a I-DnaB interaction mediates rapid replication fork movement $\mathrm{Ce} / 1$ 1996, 84:643650 .

53. Dong F, Weitzel SE, von Hippel PH: A coupled complex of T4 DNA replication helicase (gp41) and polymerase (gp43) can perform rapid and processive DNA strand-displacement synthesis. Proc Nat/ Acad Sci USA 1996, 93:14456-14461.

54. Dong F, von Hippel PH: The ATP-activated hexameric helicase of bacteriophage T4 (gp41) forms a stable primosome with a single subunit of T4-coded primase (gp61). I Biol Chem 1996 271:19625-19631.

Post-print standardized by MSL Academic Endeavors, the imprint of the Michael Schwartz Library at Cleveland State University, 2017. 